\title{
The antigenic activity of some poliomyelitis vaccines used in the United Kingdom in 1958
}

\author{
BY E. J. C. KENDALL \\ Medical Officer, Epsom College, Epsom \\ R. L. VOLLUM \\ Public Health Laboratory, Oxford \\ AND T. S. L. BESWICK, ANN MILLER AND J. O'H. TOBIN \\ Biological Standards Control Laboratory, Medical Research Council \\ Laboratories, Hampstead, N.W.3 \\ (Received 13 June 1960) \\ Numerous reports on the antibody response to poliomyelitis vaccines produced \\ in different parts of the world have been published, but few show the relation \\ between vaccine potency and efficacy in man (Salk, 1959). From the antibody \\ studies reported here and elsewhere, some indication of this relation can be \\ obtained (Report, 1959; Kendall, Beswick, Miller \& Tobin, 1960).
}

\section{MATERIALS AND METHODS}

Subjects

The subjects consisted of fourteen young medical personnel and 172 public schoolboys aged 13-18 years, who had no detectable antibody to any of the three types of poliovirus before vaccination at a serum dilution of 2 , and forty schoolboys with antibody to Type 2 but none to Types 1 and 3 . Not all subjects were available for the collection of a serum sample each time or completed the full vaccination course.

\section{Vaccines}

Four British, two Canadian and two American commercial poliomyelitis vaccines (vaccines $A$ to $H$ ) were compared with an experimental vaccine $\left(S_{2}\right)$ fortified by the addition of extra Type 1 component. This experimental vaccine was made up from British vaccine $\mathrm{H}$ mixed together with an equal quantity of Type 1 component. For the primary course of vaccination two doses each of $1 \mathrm{ml}$. of the commercial vaccines $A$ to $H$ and $2 \mathrm{ml}$. of the special vaccine, $S_{2}$, were given. The amount of Type 1 antigen in each dose of $S_{2}$ was approximately three times that in each dose of vaccine $H$. The Type 2 and 3 components were similar in each. All the medical personnel and seven of the schoolboys received the experimental vaccine.

A single British commercial vaccine, different from those used for the primary course, was used for the booster dose, except in the case of twelve of the medical 
personnel, who had been given $S_{2}$ previously. These subjects received an additional $0.5 \mathrm{ml}$. of monovalent Type 1 component, which was mixed with the commercial trivalent vaccine in the syringe at the time of injection.

\section{Time-table of injections and bleedings}

The primary course of two doses of vaccine was administered intramuscularly into the upper arm at an interval of approximately 4 weeks. It was followed 9-12 months later by a third booster dose. Blood samples were taken before the first dose, 2 weeks after the second dose and at the time of, and 2 weeks after, the booster dose.

As a responsibility was owed to the boys being vaccinated, an extra dose of vaccine was given 4-9 weeks after the second dose to all those who failed to produce a titre of more than 4 to the first two injections. They also received a booster dose at the same time as the others. Vaccine $F$ was used for this extra dose.

\section{Serum antibody titrations}

All the first and second serum samples were tested by the 'cytopathic test', two tubes being used for each fourfold serum dilution. All the second serum samples from these bleeds were tested for each Type in the same batch of cells and in the same test at dilutions from $1 / 4$ to $1 / 4096$. All those with titres of less than 4 were retested at a dilution of 2 . Titres are given as the initial serum dilution neutralizing virus and not that of the final serum-virus mixtures, as in previous publications from this laboratory.

The pre- and post-booster dose (third and fourth) serum samples were tested at similar dilutions by the galactose colour test, all titrations for each Type being done in the same test. The results of the second, third and fourth serum samples were linked by including twenty sera from the second bleeding in the tests of the third and fourth bleedings. These two techniques for titrating poliomyelitis antibodies give similar results (Perkins \& Evans, 1959).

\section{RESULTS}

The titres obtained with each vaccine for each Type are given in Tables 1-3, those from boys who received an extra dose between the second and third bleedings being noted by the numbers in brackets in rows three and four of vaccines $A, B$, $\mathrm{C}, \mathrm{D}, \mathrm{F}$ and $\mathrm{H}$. None of the subjects given vaccine $\mathrm{E}, \mathrm{G}$ or $\mathrm{S}_{2}$ or with pre-existing Type 2 antibody received an extra dose as part of the primary course. The titres of those people who had vaccine $S_{2}$ initially and received reinforced vaccine for their third booster dose are given in square brackets. An analysis of these results is given in Tables $4-6$.

\section{DISCUSSION}

The exact relationship between poliomyelitis antibody levels in man and protection against paralytic disease is not known. In the field trial held in the United Kingdom (Report, 1957a) the vaccines used gave $80 \%$ protection during the season following inoculation with two doses, but produced antibody levels in 


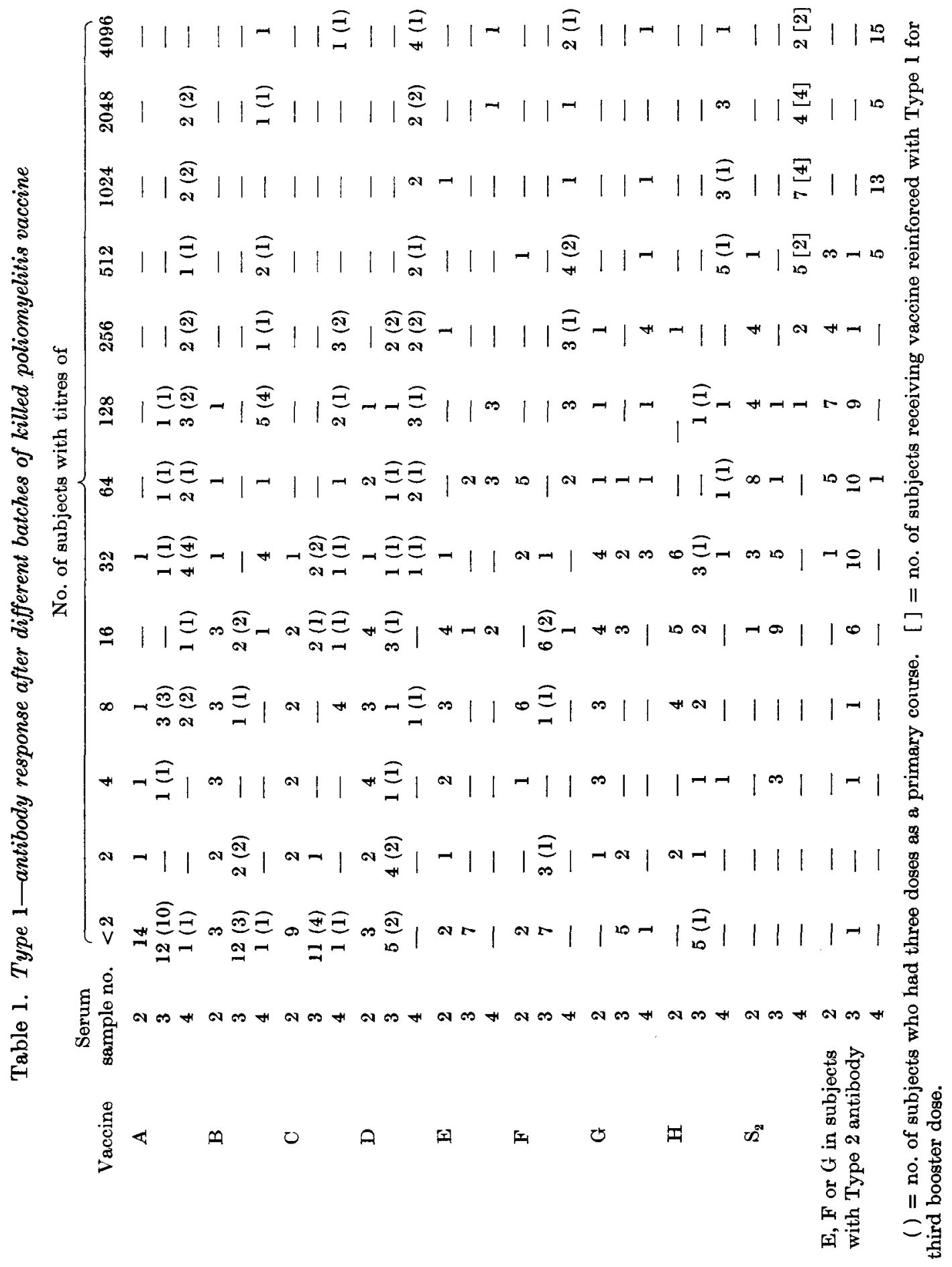




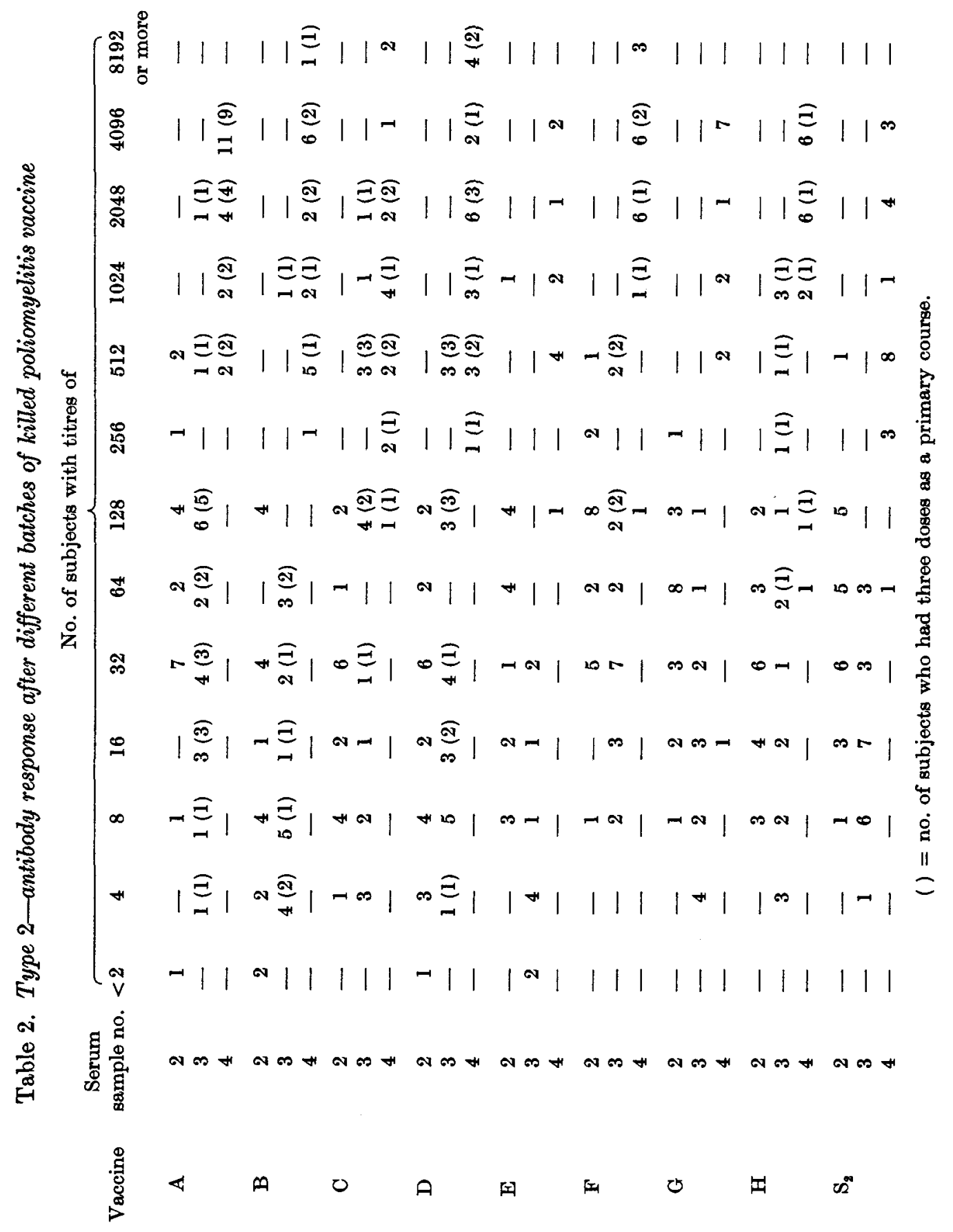




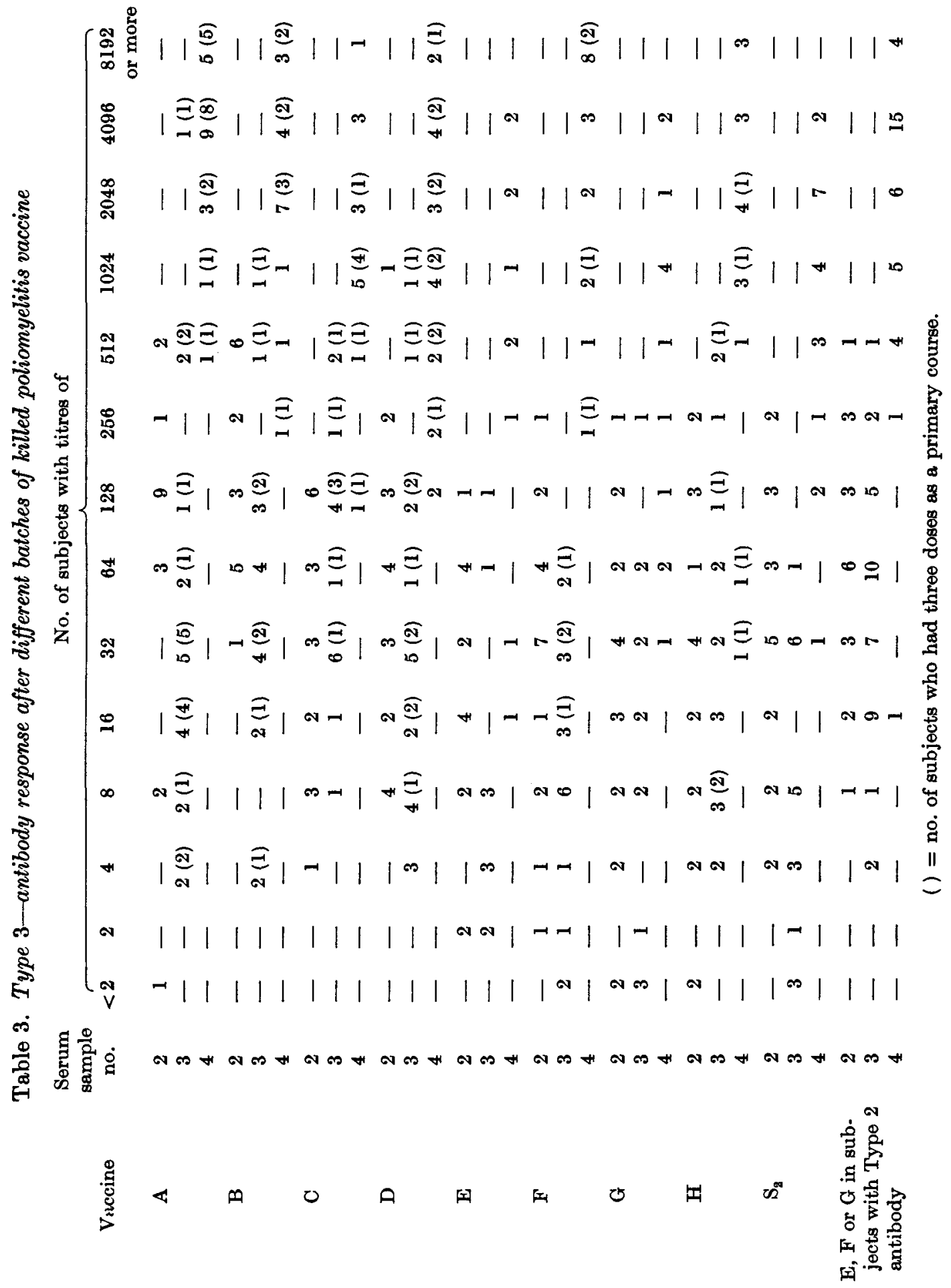




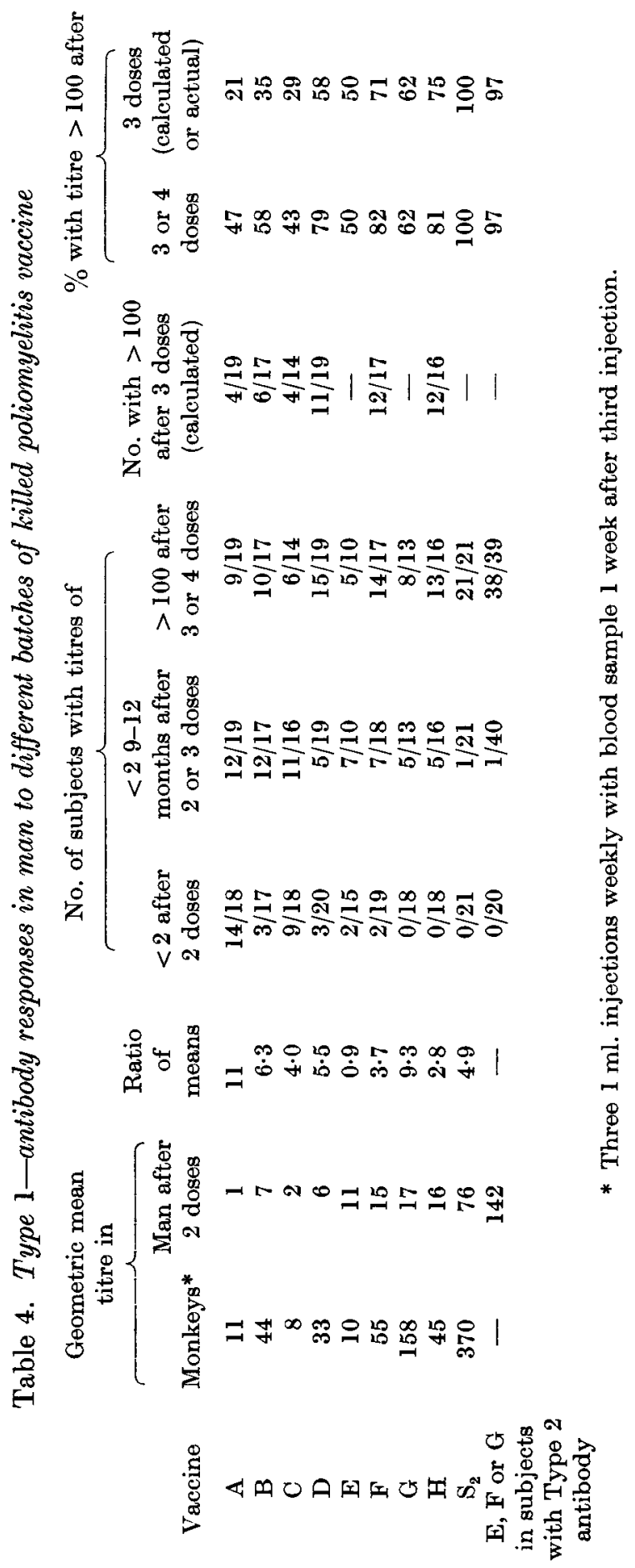


$98 \%$ of the 197 children tested (Report, 1957b). This would indicate that low levels of antibody after the initial course of injections were not always protective and suggested that subjects without detectable antibody levels were not immune to the paralytic form of poliomyelitis. It has been argued that after vaccination,

Table 5. Type 2-antibody responses in man to different batches of killed poliomyelitis vaccine

\begin{tabular}{|c|c|c|c|c|c|c|c|}
\hline & & & & No. & f subjects with & titres of & \\
\hline Vaccine & $\overbrace{\text { Monkeys }}^{\text {Geom }}$ & $\underbrace{\text { etric }}_{\text {Man }} \begin{array}{l}\text { tre in } \\
\text { nan }\end{array}$ & $\begin{array}{c}\text { Ratio } \\
\text { of } \\
\text { means }\end{array}$ & $\begin{array}{c}<4 \\
\text { after } \\
2 \text { doses }\end{array}$ & $\begin{array}{c}<4 \\
9-12 \text { months } \\
\text { after } 2 \\
\text { or } 3 \text { doses }\end{array}$ & $\begin{array}{c}>100 \\
\text { after } 3 \\
\text { or } 4 \text { doses }\end{array}$ & $\begin{array}{c}\text { \% producing } \\
\text { titre }>100 \\
\text { after } 3 \text { or } \\
4 \text { doses }\end{array}$ \\
\hline $\mathbf{A}$ & 168 & 55 & $3 \cdot 0$ & $1 / 18$ & $0 / 19$ & $19 / 19$ & 100 \\
\hline B & 93 & 16 & $5 \cdot 8$ & $2 / 17$ & $0 / 16$ & $17 / 17$ & 100 \\
\hline C & 145 & 23 & $6 \cdot 3$ & $0 / 16$ & $0 / 15$ & $14 / 14$ & 100 \\
\hline D & 83 & 17 & $4 \cdot 9$ & $1 / 20$ & $0 / 19$ & $19 / 19$ & 100 \\
\hline $\mathbf{E}$ & 29 & 49 & $0 \cdot 6$ & $0 / 15$ & $2 / 10$ & $10 / 10$ & 100 \\
\hline $\mathbf{F}$ & 117 & 83 & $1 \cdot 3$ & $0 / 19$ & $0 / 18$ & $17 / 17$ & 100 \\
\hline $\mathbf{G}$ & 390 & 60 & $5 \cdot 8$ & $0 / 18$ & $0 / 13$ & $12 / 13$ & 92 \\
\hline $\mathbf{H}$ & 102 & 29 & $3 \cdot 5$ & $0 / 18$ & $0 / 16$ & $15 / 16$ & 94 \\
\hline $\mathrm{S}_{2}$ & 118 & 51 & $2 \cdot 3$ & $0 / 21$ & $0 / 20$ & $19 / 20$ & 95 \\
\hline
\end{tabular}

Table 6. Type 3-antibody responses in man to different batches of killed poliomyelitis vaccine

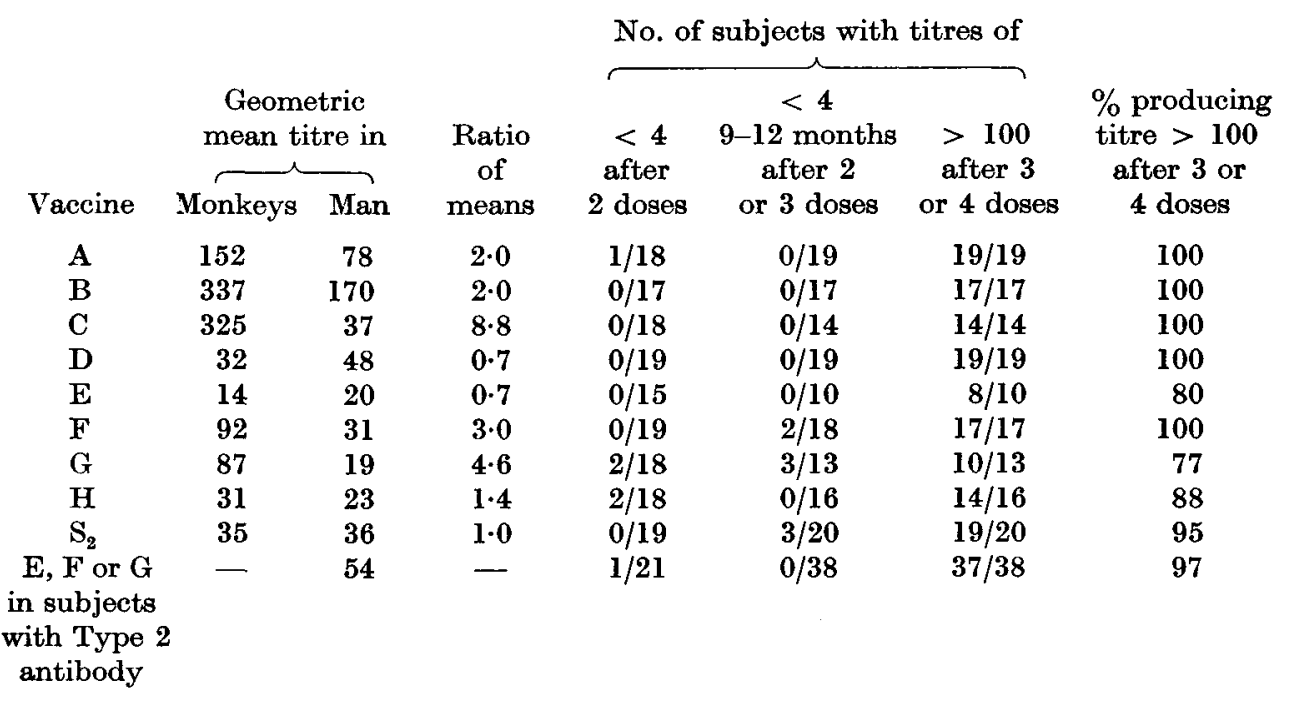

even in the absence of antibody, a sensitized state remains which, in poliomyelitis, is protective, although it has not been shown to be effective in other diseases (Report, 1959). Moreover, it has been demonstrated that the antibody response after feeding live attenuated poliovirus was no quicker in those previously vaccinated with killed vaccine than in unvaccinated non-immune individuals (Sabin, 1958) and that after a dose of killed vaccine the antibody rise occurred at 
the same time in those vaccinated subjects who had lost their vaccine-induced antibody as in unvaccinated subjects (Report, 1959). Until evidence to the contrary is forthcoming it must be assumed that susceptible people vaccinated with killed vaccine are only immune as long as they have detectable antibody in their blood. It is generally agreed that the purpose of vaccination is to ensure this state (Proceedings of a Symposium, 1959).

The percentage of subjects producing antibody after two doses of vaccines A-H varied from 22 to $100 \%$ for Type I (Table 4), from 85 to $100 \%$ for Type 2 (Table 5), and from 88 to $100 \%$ for Type 3 (Table 6). In those receiving only two doses, $54 \%$ still had detectable antibody to Type 1 when the booster dose was given compared with 97 and $90 \%$ with antibody to Types 2 and 3 . It can be seen that at this time, none of the commercial vaccines used was potent enough to ensure detectable Type 1 antibody levels in more than $75 \%$ of those vaccinated with them, while in those receiving the reinforced vaccine $S_{2}$ all except one had detectable antibody. This one exception had antibody 3 months before his third booster dose was given and gave a reasonable response to it. In spite of an extra dose in those who responded with levels of 4 or less, $40 \%$ of these subjects had no Type 1 antibody at the time of the booster dose. This percentage would have been even higher if the extra dose had not been given.

It has been shown previously (Report, 1959) that subjects without detectable Type 1 antibody tend to respond poorly to a third dose when compared with those with antibody and this has been confirmed in this group of subjects (Beswick, 1959). The recent studies by Kendall and his colleagues (1960) in adolescents and by Logan, Field, Macrae, Miller \& Tobin (1960) in children indicated that the persistence of antibody after a third dose depends on the level induced. For all types the average fall was about $80 \%$ in 18-24 months, so that if this decline was continued at the same rate the $1 \%$ level would be reached in about 5 years. If detectable antibody is to be present 5 years after a booster dose, the vaccine used should induce a titre of at least 1 in 100 for each type. This titre was the minimum level found by us after natural poliomyelitis infection, the lowest titre which maintained detectable antibody in all subjects two years after a booster dose (Kendall et al. 1960), and the lowest titre obtained with experimental vaccine $S_{2}$. The percentages of subjects producing this titre to Type 1 with the different vaccines are given in Table 4 for those who received three or four doses, and are calculated for them as though none had been given an extra dose. In making this calculation, it was presumed that all those given a third initial dose because of a Type 1 level of 4 or less would have lost antibody by the time of their booster dose and that their response to it would have been similar to those in the group who had lost their antibody and who had had only two doses before the booster. Two-thirds of these subjects did not reach a titre of $>100$ after the third dose. Twenty of twenty-two subjects who had titres of 8 after the initial course and so were not given an extra dose of vaccine had no detectable antibody at the time of the booster dose. This calculation does not affect the general interpretation of results, but is considered to give a more comparable picture of the Type 1 responses of the different vaccines. As can be seen, the response to the booster dose is related 
to the percentage of those with Type 1 antibody at the time of injection, which in turn is related to the potency of the vaccine used for the initial course.

The well-known enhancing effect of pre-existing Type 2 antibody on the Type 1 response to vaccination was again demonstrated, while its effect on the Type 3 response was less evident (Tables 4, 6 above; Salk, 1956; Russell, 1958).

It is not so easy, or important, to make similar comparisons for the Types 2 and 3 components of the vaccines studied as all contained potent antigens for both these types (Tables 5, 6). Only four subjects failed to produce antibody to Type 2 and five to Type 3 after the primary course. Of those who did not have an extra dose only two were without Type 2 antibody and eight without Type 3 a year later. Only three subjects failed to produce titres of $>100$ to Type 2 and eight to Type 3 after the booster dose. With such small numbers of poor responders, any comparison between vaccines is difficult. It can be said, however, that although there was a considerable variation in their potency to these types, all the vaccines tested were found adequate in their Type 2 and 3 components, producing in nearly all subjects a good response, with titres of $>100$ after a booster dose.

None of the Type 1 components of any of the commercial vaccines were as good as the experimental vaccine $S_{2}$, indicating that increased amounts of Type 1 antigen will be required before vaccines can be said to be completely satisfactory. The potency of vaccines produced recently in this country and those imported from North America has increased, most now having an antigenicity approaching vaccine $H$ for Type $I$ and above it for Types 2 and 3 . Such vaccines should give about $85 \%$ 'protection' for at least 5 years, as judged by the presence of detectable antibody in the blood of those vaccinated (Kendall et al. 1960). By increasing the potency of the Type 1 component to that of $S_{2}$, or by giving a fourth dose within a year of the third, this protection could be raised to over $95 \%$. In the United Kingdom the introduction of an adequate minimum standard for potency for poliomyelitis vaccine has not been possible in the past as demand has exceeded supply. With increased supplies, more rigorous control of potency becomes urgent, especially as some of the vaccines below the potency of vaccine $H$ are still being produced. Work is now in progress in order to introduce this, or a similar vaccine, as a minimum standard for potency in this country. As can be seen from Tables 4, 5 and 6 , the ratios of response in men and monkeys are too variable to detect anything except large differences. This is not because the monkey is a poor animal for antigenicity tests, but merely that the twelve monkeys used form an inadequate sample. Other less-expensive animals are suitable and can be used in the numbers required for more accurate tests, the choice of species depending on the cost and ease of supply and handling (Gard, 1958; de Somer, Maeyer \& Prinzie, 1958; Soloviev \& Gendon (1960).

The results reported here were obtained from studies in adolescents and adults who appear to respond somewhat less well to the primary course than children, and the conclusions may therefore be on the pessimistic side for younger subjects. They do not apply to infants, in whom killed vaccine is not as effective as in the other age groups (Perkins, Yetts \& Gaisford, 1958). 


\section{SUMMARY}

The potency in man of eight different commercial vaccines and an experimental vaccine, as judged by the antibody response after the primary course of two injections and after a booster dose 9-12 months later, was compared. All the vaccines produced good responses to Types 2 and 3 but some were less satisfactory for Type 1. The relation of potency to protection in man is discussed and the use of one of the vaccines as a minimum standard for this country is suggested.

Our thanks are due to the Headmasters and Medical Officers of Aldenham and Mill Hill Schools and to the Headmaster of Epsom College for their co-operation, and to those people who so kindly volunteered for this study; to the Ministry of Health and Dr W. Wood, O.B.E., for supplying the commercial and experimental vaccines respectively; to Miss Olive Stanbridge for technical assistance, and to Dr F. T. Perkins for the results of the monkey potency tests.

\section{REFERENCES}

Beswick, T. S. L. (1959). Proceedings of the European Society against Poliomyelitis, 1959 (to be published).

GaRd, S. (1958). Arch. virusforsch. 8, 411.

Kendale, E. J. C., Beswick, T. S. L., Mrrler, Ann \& Tobin, J. O'H. (1960). Brit. med. J. i, 1689.

Logan, J. S., Fietd, Anne M., Macrae, A. D., Miller, Ann \& Tobin, J. O'H. (1960). Brit. med. J. i, 1692.

Perkins, F. T. \& Evans, D. G. (1959). Brit. med. J. i, 1549.

Perkins, F. T., Yetts, Risha \& Gaisford, W. (1958). Brit. med. J. ii, 68.

Proceedings of a Symposium on Immunization in Chindhood (1959). Wellcome Foundation, pp. 38-58. Edinburgh: E. \& S. Livingstone.

REPort mom the Biological Standards Control Laboratory (1959). Brit. med. J. i, 609.

Report to the Medicat Research Councti (1957a). Brit. med. J. i, 366.

Report to the Medical Research Council (1957b). Brit. med. J. ii, 1207.

Russelt, K. (1958). Brit. med. J. i, 622.

Sabin, A. B. (1958). Advanc. Paediatrics, 10, 197.

SALK, J. E. (1956). Amer. J. med. Sci. 232, 369.

SALK, J. E. (1959). J. Amer. med. Ass. 169, 1829.

Soloviev, V. D. \& Gendon, U. Z. (1960). Bull. Wld Hith Org. 22, 291.

Somer, P. De., Maeyer, E. De \& Prinzie, A. (1958). Arch. virusforsch. 8, 430. 